\title{
Bicuspid aortic valve repair using geometric ring annuloplasty: A first-in-humans pilot trial
}

\author{
J. Scott Rankin, MD, ${ }^{\mathrm{a}}$ Domenico Mazzitelli, MD, ${ }^{\mathrm{b}}$ Theodor J. M. Fischlein, MD,${ }^{\mathrm{c}}$ Yeong-Hoon Choi, MD, ${ }^{\mathrm{d}}$ \\ Diana Aicher, MD, ${ }^{\mathrm{e}}$ Lawrence M. Wei, MD, ${ }^{\mathrm{a}}$ and Vinay Badhwar, $\mathrm{MD}^{\mathrm{a}}$
}

\section{ABSTRACT}

Objective: As bicuspid aortic valve (BAV) repair evolves, more effective annular reduction and stabilization could be advantageous. A geometric annuloplasty ring has been developed, and 2-year regulatory outcomes of a first-in-humans pilot trial are reported.

Methods: A prospective first-in-humans trial of BAV ring annuloplasty was completed in 16 patients. Patient age was $44.4 \pm 11.3$ (mean \pm standard deviation) years, preoperative aortic insufficiency grade was $2.5 \pm 1.0$, New York Heart Association class $1.8 \pm 0.4$, and mean systolic gradient $13.4 \pm 12.9 \mathrm{~mm} \mathrm{Hg}$. Three patients had Sievers type o BAV, 11 had type 1, and 2 were type 2. The Dacron-covered titanium rings had circular base geometry with $180^{\circ}$ subcommissural posts and were implanted subannularly. Leaflets were reconstructed using plication/cleft closure, creating an effective height of $\geq 8 \mathrm{~mm}$, even if modest gradients were induced.

Results: Mean pre-repair annular diameter was $28.6 \pm 3.3 \mathrm{~mm}$, and the average ring diameter was $22.3 \pm 1.6 \mathrm{~mm}$. All valves required leaflet plication/reconstruction; pericardium was avoided; and 7 patients had aortic replacement for aneurysms. No early mortalities or major complications occurred. Two patients required early prosthetic valve replacement for technical errors, and all were between 24-38 months' postoperative at follow-up. No late mortalities or valve-related complications occurred, and all patients reverted to New York Heart Association class I. Aortic insufficiency reduction was significant to grade $0.9 \pm 0.5$ at 2-years $(P<.0001)$. Mean valve gradients were acceptable $(13.3 \pm 5.0 \mathrm{~mm} \mathrm{Hg}$ at 2 years; overall $P=.11)$ and tended to fall over time $(P<.0001)$.

Conclusions: Geometric ring annuloplasty was safe and effective for BAV repair. Al reduction was significant, valve gradients were satisfactory, and clinical outcomes

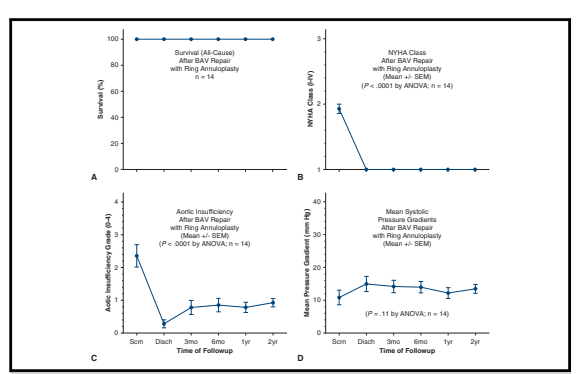

Outcomes observed over 2 years after BAV repair using geometric ring annuloplasty.

CENTRAL MESSAGE

BAV repair supported by geometric ring annuloplasty is associated with excellent 2-year

\section{outcomes.}

\section{PERSPECTIVE}

Techniques now exist to repair most types of BAV disease with potentially improved long-term results as compared with prosthetic valve replacement.

See Commentary on page 26. were excellent. Geometric ring annuloplasty could simplify and standardize BAV repair. (JTCVS Techniques 2020;1:18-25)

Video clip is available online.

Compared with aortic valve replacement (AVR), aortic valve repair is associated with fewer valve-related

From the ${ }^{\mathrm{a}}$ Department of Cardiovascular and Thoracic Surgery, West Virginia University Heart and Vascular Institute, Morgantown, WVa; ${ }^{\mathrm{b}}$ Department of Cardiac Surgery, Klinikum Bogenhausen, Munich, Germany; ${ }^{c}$ Department of Cardiovascular Surgery, Klinikum Nürnberg, Paracelsus Medical University, Nürnberg, Germany; ${ }^{\mathrm{d}}$ Department of Cardiac and Thoracic Surgery, University of Köln, Köln, Germany; and ${ }^{\mathrm{e}}$ Department of Cardiac Surgery, HGZ Bad Bevensen Herzchirurgie, Bad Bevensen, Germany.

The research was supported by BioStable Science and Engineering (BSE), Inc, Austin Tex (www.biostable-s-e.com). The sponsor had a role in choosing the surgical investigators and study design, and in the decision to submit the report for publication in the surgical literature. The sponsor did not have a role in the collection of the data, which was done by the independent clinical nurses at each center, nor with the interpretation of data, nor the writing of this report. This multicenter clinical complications $^{1,2}$ and better risk-adjusted long-term survival. ${ }^{3-5}$ The development of bicuspid aortic valve (BAV) repair has been especially important, since patients with BAV tend to be younger and are not good candidates for tissue AVR because of early prosthetic degeneration nor mechanical AVR because of life-long anticoagulation requirements. Outcomes with the Ross operation for BAV disease have been satisfactory, ${ }^{6}$ but this procedure exposes

trial of the HAART 200 ring was performed in Germany, and the device is now approved by the Food and Drug Administration in the United States (21 CFR 870.3800).

Received for publication Oct 28, 2019; revisions received Oct 28, 2019; accepted for publication Dec 13, 2019; available ahead of print Feb 17, 2020.

Address for reprints: J. Scott Rankin, MD, Department of Cardiac and Thoracic Surgery, WVU Heart and Vascular Institute, West Virginia University, 1 Medical Center Dr, Morgantown, WV (E-mail: jsrankinmd@cs.com). 2666-2507

Copyright (C 2020 The Author(s). Published by Elsevier Inc. on behalf of The American Association for Thoracic Surgery. This is an open access article under the CC BY-NC-ND license (http://creativecommons.org/licenses/by-nc-nd/4.0/). https://doi.org/10.1016/j.xjtc.2019.12.005 


\section{Abbreviations and Acronyms}

$\mathrm{AI}=$ aortic insufficiency

$\mathrm{AVR}=$ aortic valve replacement

$\mathrm{BAV}=$ bicuspid aortic valve

patients to the long-term complications of 2 operated valves: the pulmonary autograft and the right ventricular conduit.

Most would agree that the development of contemporary BAV repair ${ }^{7}$ has been a major advance. Yet, problems continue to exist, such as reconstruction of BAVs with relatively equal-sized sinuses ${ }^{8}$ the need to add pericardial tissue that may fail, ${ }^{9,10}$ late annular dilatation in the absence of root stabilization, ${ }^{11}$ and the relative efficacy of annuloplasty techniques. ${ }^{12-15}$ To address these issues, an internal geometric annuloplasty ring for use in BAV repair has been developed and tested in a prospective first-in-humans pilot trial. ${ }^{16}$ The purpose of this paper is to report the final 2-year regulatory outcomes of that trial as a preliminary to developing a pivotal clinical investigation.

\section{METHODS}

The BAV ring was computer-machined from a solid block of titanium and covered with a thin layer of polyester to promote endothelialization. It had circular base geometry and two $180^{\circ}$ subcommissural posts (Figure 1). The design of the ring was generated from multiple sources. First, the curvature, height, and geometry of the subcommissural posts were derived from computed tomographic angiographic studies of normal trileaflet aortic valves, ${ }^{17}$ and these aspects were taken directly from the design of the trileaflet ring. ${ }^{18}$ Thus, curvatures, post heights (equal to one radius of the valve base), and the $10^{\circ}$ outward flare were the same as the trileaflet ring.

The second design source consisted of pre- and postoperative computed tomographic angiograms in 10 patients undergoing successful BAV repair with subcommissural annuloplasty. Representative scans from these patients generally showed an elliptical annulus preoperatively, with the long axis of the ellipse in the sinus-to-sinus direction (Figure 2). No matter the preoperative annular configuration, the competent postrepair BAVs tended to assume circular base geometry with closer to $180^{\circ}$ commissures. Therefore, the ring was designed with these features.

The sample size calculation for this safety and efficacy pilot study was taken from an antecedent trial of trileaflet ring annuloplasty, ${ }^{19}$ in which the treatment effect was sufficient to define a statistical benefit with a $90 \%$ power and $P$ value of $<.05$ with 16 patients. Consequently, 16 patients with bicuspid valves were recruited into the study with liberal selection criteria; the only exclusions were active infection and heavy calcification. All protocols were approved by the German Federal Regulatory body (BfArM) and local ethics committees (ClinicalTrials.gov: NCT02071849). Every patient was counseled extensively and provided signed informed consent.

Baseline age was $44.4 \pm 11.3$ (mean \pm standard deviation) years, aortic insufficiency (AI) grade was $2.5 \pm 1.0$, New York Heart Association class was $1.8 \pm 0.4$, and mean systolic gradient was $13.4 \pm 12.9 \mathrm{~mm} \mathrm{Hg}$ (Table 1). Three patients had Sievers type 0 valves, 11 had Sievers type 1 valves, and 2 had Sievers type 2. Thirteen patients had left-/rightcoronary cusp fusion, 1 had right-/noncoronary cusp fusion, and 2 had both (unicuspid valves). Moderate-to-severe AI was present in 12 of the

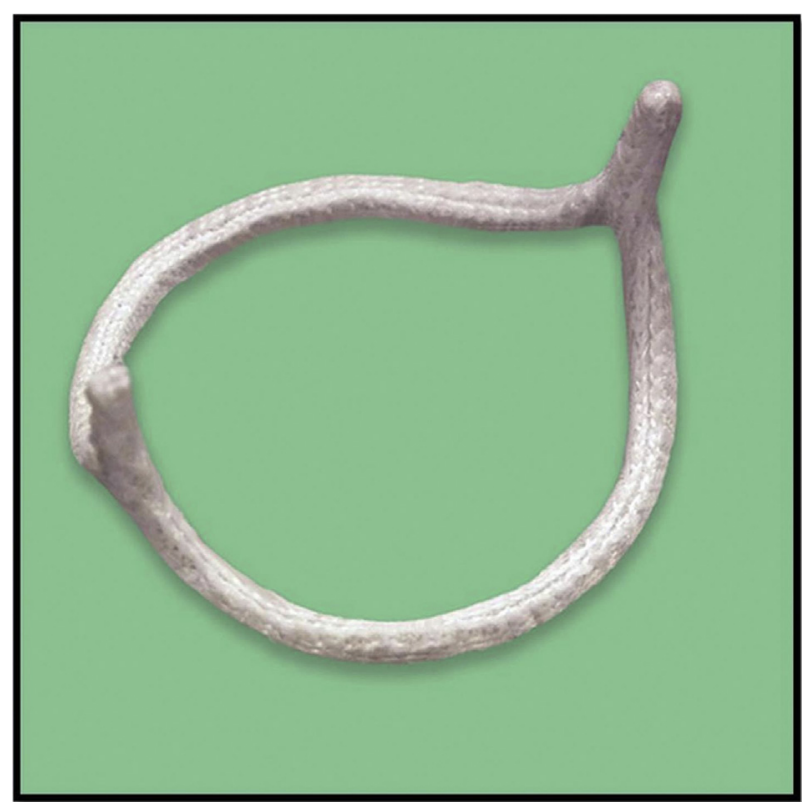

FIGURE 1. A bicuspid aortic valve annuloplasty ring with circular base geometry and two $180^{\circ}$ subcommissural posts.

16 cases, and 4 had mild AI associated with aortic aneurysms. Ascending aortic and/or root aneurysms were replaced in 7 of the 16 patients, using Dacron grafts $7 \mathrm{~mm}$ larger than the chosen ring. For bicuspid root aneurysms, remodeling Valsalva grafts were fashioned with 2 approximately equal sinus tongues ${ }^{20}$ (Table 1), except for asymmetric root aneurysms, where only the enlarged nonfused sinus was selectively replaced.

Ring implantation technique has been described elsewhere, ${ }^{16}$ but to summarize, the required ring diameter was estimated by measurement of nonfused cusp free-edge length (L), using ball sizers in the sinus of Valsalva. Bicuspid ring size was based on the following formula: required ring diameter $=\mathrm{L} / 1.8 .{ }^{21}$ In most patients, annular base geometry was usually elliptical, ${ }^{16}$ with the sinus-to-sinus diameter being the long axis of the ellipse (Figure 2). The 2 ring posts were sutured into the annuli of the subcommissural triangles (straddling the nonfused leaflet) with transannular horizontal mattress sutures of 4-0 PROLENE (Figure 3) supported with fine supra-annular Dacron pledgets (Video 1). The ring then was passed below the annulus, and 5 to 7 looping mattress sutures were placed deeply through the sinus aspect of both annuli, $2 \mathrm{~mm}$ deep to the leaflet-aortic junction. All annular sutures were tied tightly over fine supra-annular Dacron pledgets and fixed laterally to prevent leaflet contact (Figure 3). ${ }^{16}$ Burying the ring posts back into the subcommissural spaces and tight apposition of the ring bodies back under the annuli prevented contact between the leaflets and ring Dacron, which could cause leaflet abrasion and repair failure. Remodeling to a circular geometry moved the sinuses centrally and recruited leaflet tissue to the midline for improved coaptation. In addition, the fused annular segment usually was larger, and differential reduction in the fused sinus annulus to the size of the nonfused sinus provided advantages for fused leaflet mobility as a $50 \%-50 \%$ annular and commissural configuration.

Bicuspid leaflet repairs usually were performed using Schäfers' techniques $^{7}$ (Video 1). After annuloplasty, type 0 valves underwent plication of both leaflets to correct prolapse. For type 1 valves, the nonfused leaflet was plicated to an effected height of $\geq 8 \mathrm{~mm}$ and used as a reference (Figure 3). When present, the fused leaflet cleft was closed linearly until similar free-edge lengths, geometric heights, and effective heights were achieved for both cusps. For type 2 valves, fused right/noncoronary 


\section{Bicuspid Valve Geometry}

\section{Pre-Repair Valve Base}

\section{Type Zero Bicuspid Valve}

\section{Type One Bicuspid Small}

\section{Type One Bicuspid Medium}

\section{Type One Bicuspid Large}

\section{Type One Bicuspid 3 Equal Sinuses}

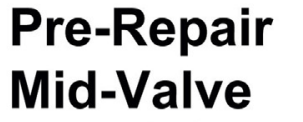

Post-Repair Mid-Valve
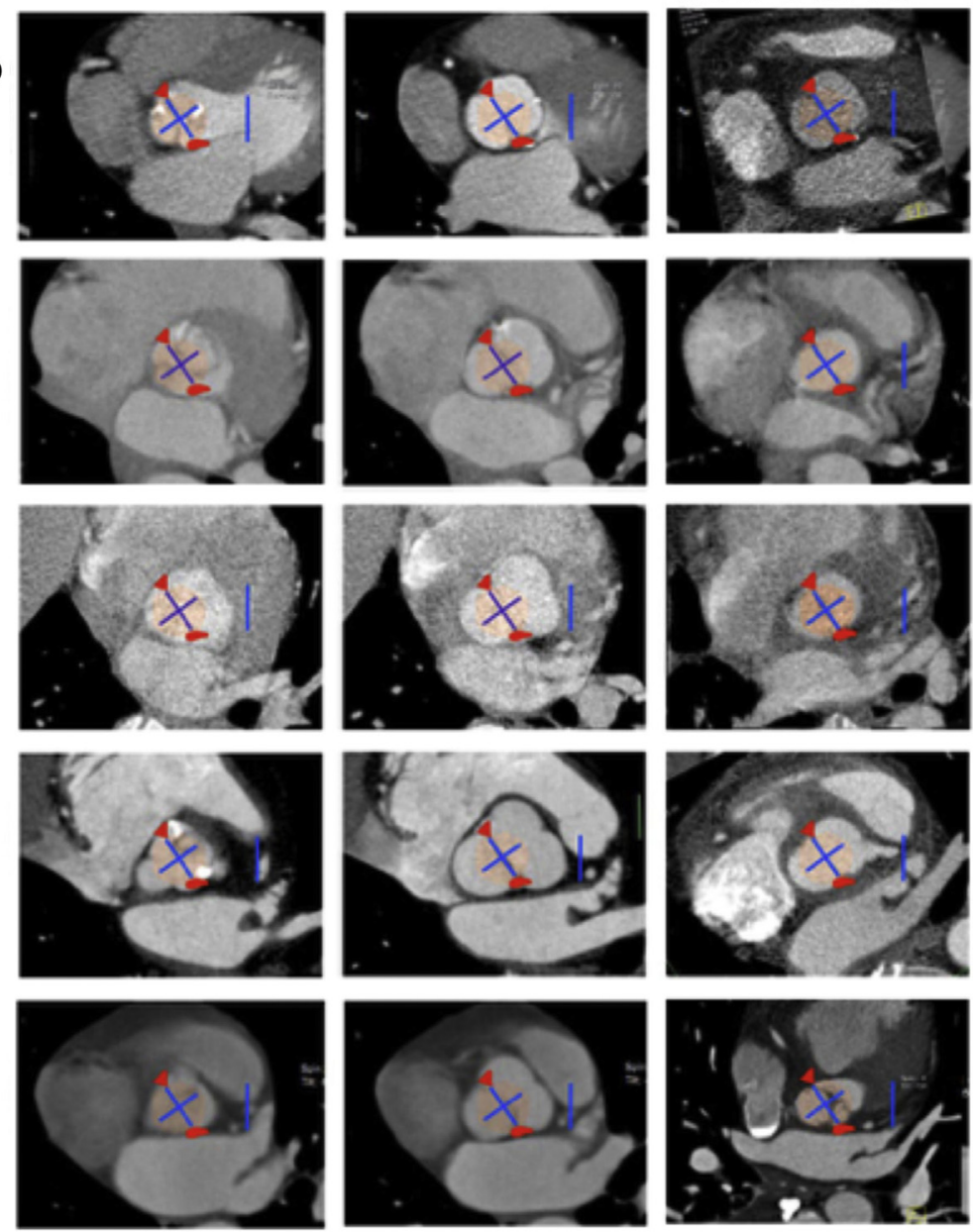

FIGURE 2. Computed tomography angiograms of representative BAV repair cases before and after repair. Patient 1 has a Sievers type 0 BAV with nearly equal sinuses and leaflets. Patients 2 to 4 have left-right fusion Sievers type 1 valves with varying degrees of annular enlargement. Patient 5 has left-right fusion with 3 equal sinuses. A 21-mm pink circle is superimposed, as well as red dots in the areas of $180^{\circ}$ commissures. At the mid-valve level after successful repair, notice the valve assumes more of a circular base geometry, with symmetrical $180^{\circ}$ commissures. These features were incorporated into the ring design.

commissurotomy was performed first, and then the valve was repaired as a type 1. A trade-off existed between effective height and magnitude of gradient. If any question existed, an effective height of $\geq 8 \mathrm{~mm} \mathrm{Hg}$ was created, and a greater gradient was tolerated. ${ }^{22}$ Glutaraldehyde-fixed autologous pericardium generally was avoided but was needed to augment leaflet defects in 3 patients. Three additional patients required debridement of leaflet calcification using the Cavitron Ultrasonic Aspirator device ${ }^{23}$ (Video 1). Only aspirin anticoagulation was administered postoperatively.

This pilot first-in-humans study was predefined for a 2-year follow-up of all clinical outcomes and echocardiographic characteristics. The primary endpoint of the trial was all-cause death, and secondary endpoints were AI reduction and mean valve gradients. An echo core laboratory provided all echo readings (MedStar Research Institute, Washington DC), using standard echo criteria and a $0-4+$ AI grading scale. ${ }^{24}$ Left ventricular dimensions and mass were derived from echocardiographic data using standard techniques. Three patients had missing preoperative valve gradients, and these were imputed to the mean for the rest. Otherwise, missing data were imputed using the last value forward technique. Changes over time in clinical and echocardiographic variables from preoperative to 2 years' postrepair were evaluated with Friedman's nonparametric analysis of variance or 2-tailed paired $t$ tests where appropriate. Analyses and graphics were performed with Prism 7.0 (GraphPad Software, Inc, San Diego, Calif), and a $P$ value of .05 was considered significant.

\section{RESULTS}

In the 16 patients with $\mathrm{BAV}$, mean pre-repair annular diameter was $28.6 \pm 3.3 \mathrm{~mm}$, and average ring diameter was $22.3 \pm 1.6 \mathrm{~mm}$, indicating significant annular dilatation in all cases (Table 1). All valves required leaflet plication and/or cleft closure. Seven had ascending aortic and/or 
TABLE 1. Baseline and early postoperative data for 16 patients with BAV repair

\begin{tabular}{|c|c|c|c|c|c|c|c|c|c|c|c|c|}
\hline \multicolumn{2}{|c|}{ Patient ID } & \multirow[b]{2}{*}{$\begin{array}{c}\text { Age, } \\
\mathbf{y}\end{array}$} & \multirow[b]{2}{*}{ Sex } & \multirow[b]{2}{*}{$\begin{array}{c}\text { Annular } \\
\text { diameter, } \\
\text { mm }\end{array}$} & \multirow[b]{2}{*}{$\begin{array}{l}\text { Ring } \\
\text { size, } \\
\text { mm }\end{array}$} & \multirow{2}{*}{$\begin{array}{c}\text { Leaflets } \\
\text { fused- } \\
\text { Sievers } \\
\text { type }\end{array}$} & \multirow[b]{2}{*}{$\begin{array}{c}\text { Leaflet } \\
\text { procedure }\end{array}$} & \multirow[b]{2}{*}{$\begin{array}{c}\text { Other } \\
\text { procedure }\end{array}$} & \multirow{2}{*}{$\begin{array}{c}\text { Pre/early } \\
\text { postoperative } \\
\text { mean gradient, } \\
\text { mm Hg }\end{array}$} & \multirow[b]{2}{*}{$\begin{array}{c}\text { Preoperative } \\
\text { AI grade } \\
0-4+\end{array}$} & \multirow{2}{*}{$\begin{array}{c}\text { Early } \\
\text { postoperative } \\
\text { AI grade } \\
0-4+\end{array}$} & \multirow[b]{2}{*}{ Comments } \\
\hline No. & $\begin{array}{c}\text { Patient } \\
\text { no. }\end{array}$ & & & & & & & & & & & \\
\hline 1 & 01-001 & 36 & M & 28 & 21 & LR-1 & $\mathrm{P}$ & ARR & $21 / 28$ & 3 & 0 & \\
\hline $2 *$ & 01-002 & 59 & M & 29 & 21 & LR-1 & P-C & & $10 / 18$ & 3 & $0 / 3$ & $\begin{array}{l}\text { Leaflet tear - } \\
\text { AVR }\end{array}$ \\
\hline 3 & 01-003 & 33 & M & 35 & 25 & LR/RN-2 & $\mathrm{AP}$ & & $35 / 27$ & 4 & 0 & \\
\hline 4 & 01-004 & 29 & M & 28 & 21 & LR-1 & P-C & & $-/ 13$ & 3 & $0 / 2$ & $\begin{array}{l}\text { ? Endocarditis } \\
\text { treated } \\
\text { medically }\end{array}$ \\
\hline 5 & 07-001 & 47 & F & 23 & 19 & LR-1 & P-C & & $8 / 25$ & 1 & 0 & \\
\hline 6 & 01-005 & 56 & $\mathrm{~F}$ & 26 & 21 & LR-1 & $P$ & ARR & $11 / 20$ & 1 & 1 & \\
\hline 7 & 07-002 & 52 & M & 27 & 23 & LR-1 & $\mathrm{P}-\mathrm{U}$ & & $6 / 13$ & 3 & 0 & \\
\hline $8^{*}$ & 01-007 & 29 & M & 28 & 23 & LR/RN-2 & $\mathrm{AP}$ & & $45 / 11$ & 2 & $0 / 3$ & $\begin{array}{l}\text { Leaflet tear - } \\
\text { AVR }\end{array}$ \\
\hline 9 & 01-008 & 47 & M & 28 & 23 & LR-0 & P-AP & ARR & $3 / 13$ & 2 & 1 & \\
\hline 10 & 08-001 & 49 & M & 29 & 23 & LR-1 & P-C & AA-HA & -122 & 4 & 0 & \\
\hline 11 & 07-003 & 41 & M & 28 & 23 & LR-0 & $\mathrm{P}$ & & $6 / 17$ & 3 & 1 & \\
\hline 12 & 01-009 & 25 & M & 27 & 21 & RN-0 & $\mathrm{P}$ & AA & $13 / 12$ & 1 & 0 & \\
\hline 13 & 07-005 & 57 & M & 25 & 21 & LR-1 & $\mathrm{P}-\mathrm{U}$ & $\mathrm{AA}$ & $5 / 10$ & 2 & 0 & \\
\hline 14 & 07-006 & 48 & M & 33 & 25 & LR-1 & $\mathrm{P}$ & ARR & $4 / 6$ & 1 & 0 & \\
\hline 15 & 01-010 & 43 & M & 35 & 23 & LR-1 & $\mathrm{P}$ & Pacer & $-/ 22$ & 3 & 0 & \\
\hline \multirow[t]{3}{*}{16} & 07-007 & 38 & M & 29 & 23 & LR-1 & $\mathrm{P}-\mathrm{C}-\mathrm{U}$ & AF Abl & $7 / 26$ & 4 & 0 & \\
\hline & Mean & 43.1 & $88 \%$ & 28.6 & 22.3 & & & $3 \mathrm{AA}$ & $13 / 17$ & 2.5 & $0.2 / 0.7$ & \\
\hline & SD & 10.6 & M & 3.3 & 1.6 & & & 4 ARR & $13 / 7$ & 1.0 & $0.6 / 1.1$ & \\
\hline
\end{tabular}

Data represent the entire 16 patients having BAV repair. Forward slash symbols in gradient data represent preoperative versus early postoperative values. Dashes are missing data. Forward slashes in postoperative AI grades represent early versus later postoperative values, after leaflet tears in 2 and after medically treated endocarditis in $1 . M$, Male; $L$, left coronary leaflet; $R$, right coronary leaflet; $A I$, aortic insufficiency; $P$, leaflet plication; $A R R$, remodeling aortic root replacement; $C$, cleft closure; $A V R$, prosthetic aortic valve replacement; $N$, noncoronary leaflet; $A P$, autologous pericardial addition to leaflet; $F$, female; $A A$, ascending aortic replacement; $H A$, hemi-arch replacement; $U$, ultrasonic decalcification; $A F A b l$, atrial fibrillation ablation; $S D$, standard deviation. *The 2 patients undergoing early reoperation for technical errors.

remodeling root replacement for aneurysms. No early or late mortalities or major complications occurred. One patient with pre-existing heart block and syncope required a pacemaker postoperatively. Two patients experienced early leaflet lacerations due to long annular suture tails, with recurrent $\mathrm{AI}$ as a technical complication (Table 1). Both were reoperated successfully for prosthetic AVR. Subsequently, a "lateral suture fixation" technique was applied (Figure 3) to avoid this complication, ${ }^{16}$ and no more suture-induced leaflet injuries occurred (now to $>700$ subsequent ring implants).

At follow-up, all patients were between 24 and 38 months postoperation, and analyses were performed with and without the 2 leaflet laceration patients included. When included, all their post-AVR missing data were imputed as the worst values observed after repair failure, penalizing this complication. Analyses are presented in Figure 4, excluding the 2 early technical failures because their repairs were lost for follow-up assessment; however, overall results were similar, and $P$ values were no different if they were included. No thromboembolism, strokes, or bleeding occurred. No late mortalities or valve-related complications were observed, and all patients reverted to New York Heart Association class I long term. Serial echocardiograms showed prolonged and stable AI reduction to grade $0.9 \pm 0.5$ at 2 years $(P<.0001)$. One patient (no. 4$)$ experienced a febrile illness late postoperatively, with leukocytosis, new appearance of central grade $2 \mathrm{AI}$, but negative cultures. He was treated with prolonged antibiotics for presumed culture-negative endocarditis and maintained a stable grade 2 leak long term without reoperation.

Generally, mean valve gradients were acceptable $(13.3 \pm 5.0 \mathrm{~mm} \mathrm{Hg}$ at 2 years; overall $P=.11$ from preoperative). In one third of patients (those with more complex anatomy such as type 2 valves with dysplastic leaflets or patients with decalcified leaflets), discharge mean gradients were 20 to $30 \mathrm{~mm} \mathrm{Hg}$ echocardiographically (Figure 5). However, gradients fell significantly over the next 2 years $(P<.0001)$, so that the highest gradients approximated $20 \mathrm{~mm} \mathrm{Hg}$ at late follow-up, presumably as 


\section{Type 1 BAV Repair}
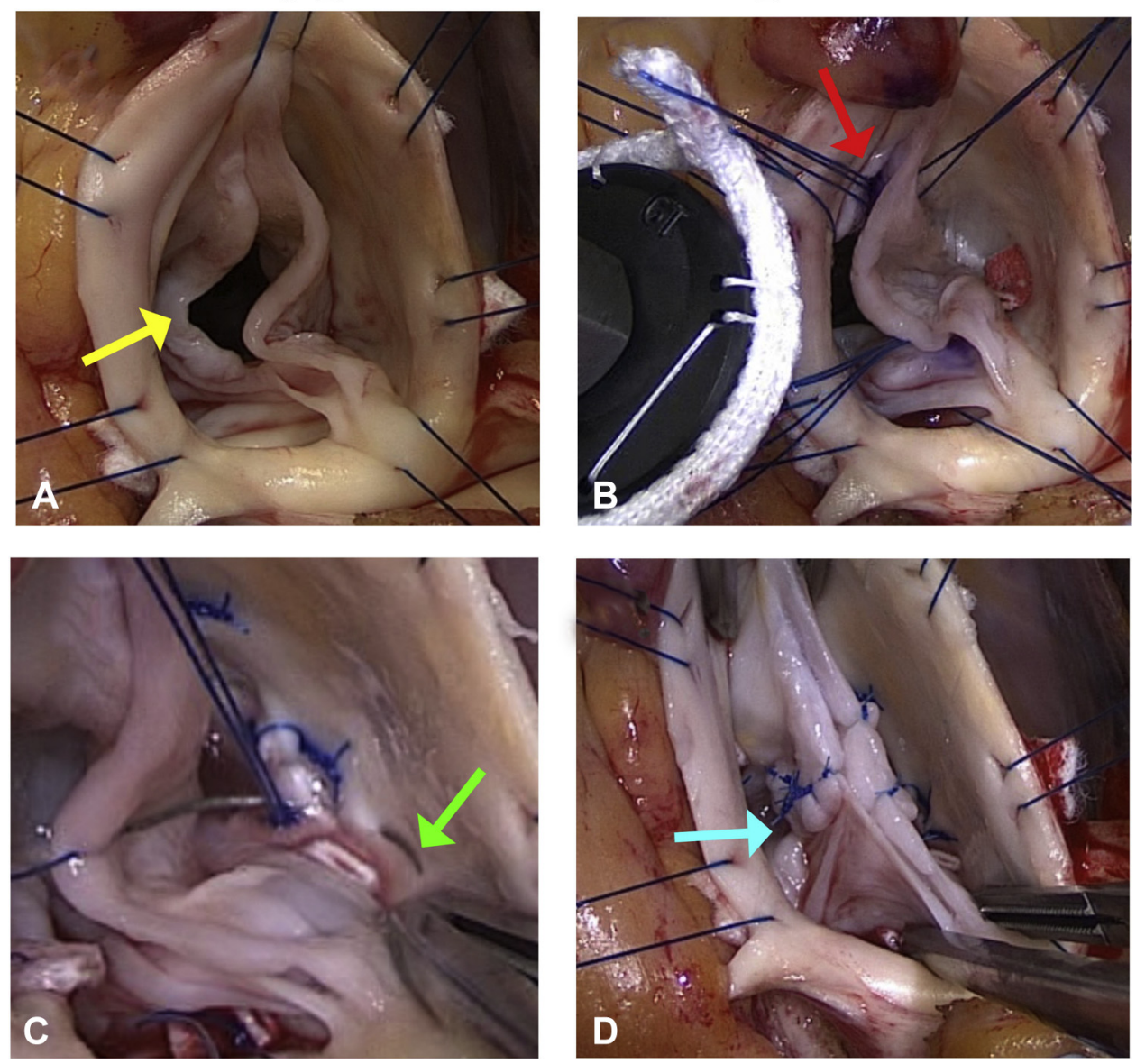

FIGURE 3. Technique of type $1 \mathrm{BAV}$ repair. A, With exposure achieved by 6 commissural and aortic sutures, a cleft in the fused leaflet (yellow arrow) is evident, as well as a redundant and prolapsing nonfused noncoronary leaflet. B. Horizontal mattress sutures bury the ring posts into the subcommissural spaces (red arrow). C, After placing annular sutures around both sinus areas, the sutures are tied over fine Dacron pledgets, and one needle is passed laterally (green arrow) and tied again to laterally fixate annular sutures away from leaflets. D, After repair, the linear closure of the fused leaflet cleft is evident (blue arrow) along with several plications on the non-fused leaflet. Importantly, the effective heights, geometric heights, and free-edge lengths of the 2 leaflets are equal. $B A V$, Bicuspid aortic valve.

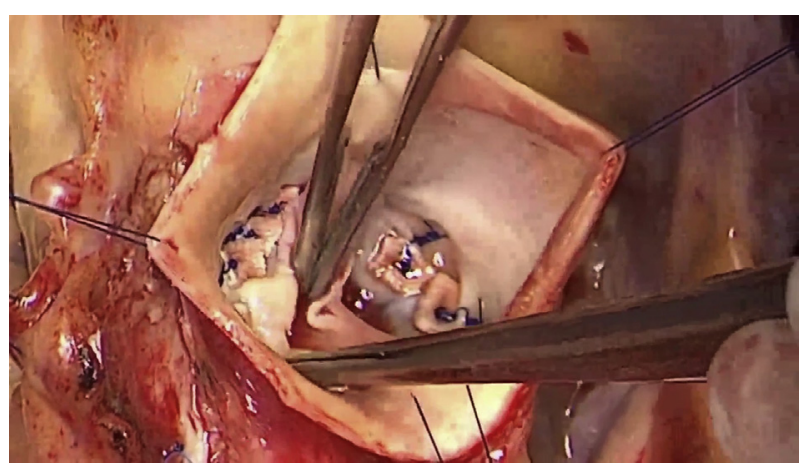

VIDEO 1. A clinical video of all the techniques employed in this paper. Video available at: https://www.jtcvs.org/article/S2666-2507(20)30023-7/ fulltext. native living leaflets adapted. All patients with significant preoperative AI experienced reductions in left ventricular dimensions and mass after repair (Table 2), even with mean gradients in the 20- to $30-\mathrm{mm} \mathrm{Hg}$ range. Patient 1 was an example in whom scarred reoperative leaflets were associated with gradients in the 20s throughout; yet, he became asymptomatic and left ventricular hypertrophy/ dilatation recovered. This operation can be viewed at: https://www.ctsnet.org/article/bicuspid-ring-annuloplastyand-leaflet-reconstruction-after-failed-bicuspid-valve-repairand. Of all echocardiographic dimensions, calculated left ventricular mass fell the most after repair, decreasing on average by a third after elimination of volume overload (Table 2; $P<.002$ ). 

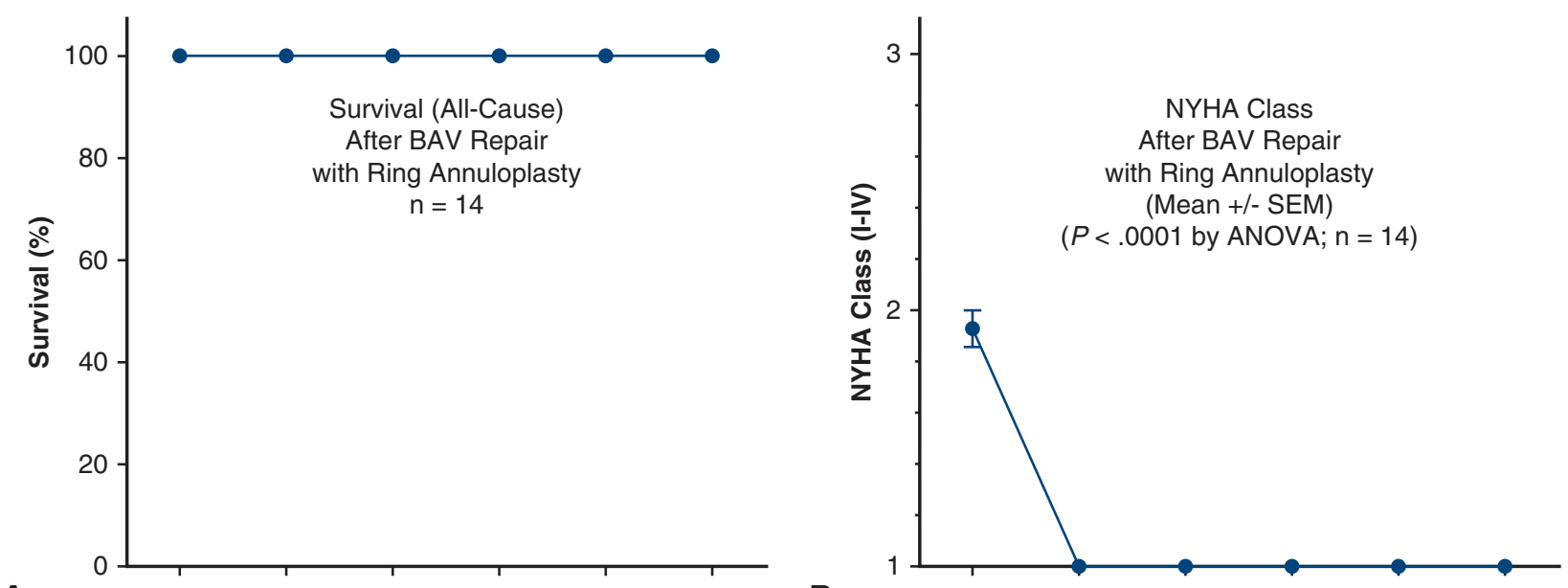

A

B
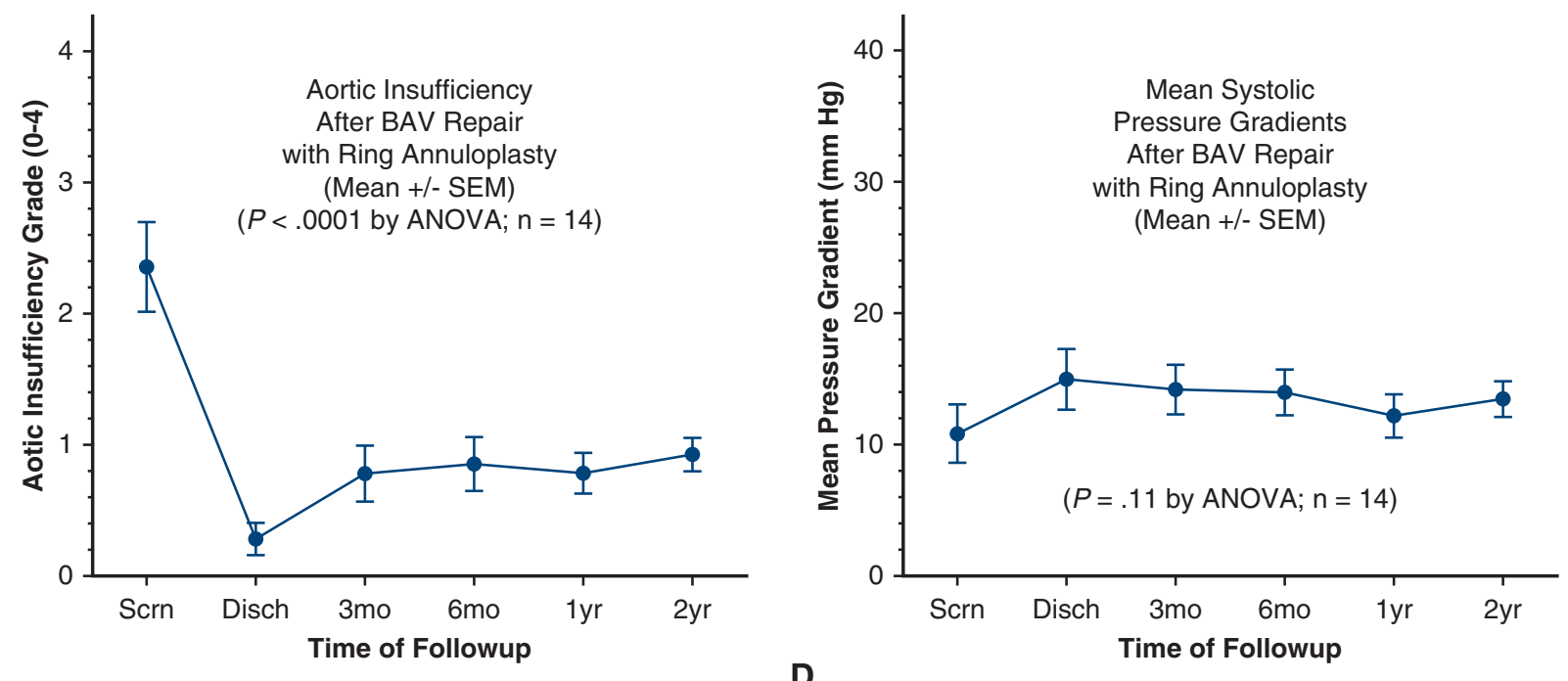

FIGURE 4. Time course of clinical and echocardiographic variables before and after BAV repair. In this analysis, the early repair failures were omitted, because their repairs were not available for assessment long term. The results, however, changed insignificantly if the 2 repair failures were included. A, Survival was excellent. B, All patients became asymptomatic. C, Average AI grade fell below 1+ and remained low. D, Mean valve gradients increased slightly immediately after annuloplasty, but overall, remained statistically unchanged by analysis of variance $(P=.11) . B A V$, Bicuspid aortic valve; $A I$, aortic insufficiency; NYHA, New York Heart Association; SEM, standard error of the mean; ANOVA, analysis of variance; Scrn, screening data; Disch, discharge data.

\section{DISCUSSION}

The development of a reproducible and stable technique of BAV repair has been a major advance in cardiac surgery. ${ }^{7,25-27}$ The first patients receiving Schäfers' techniques for leaflet reconstruction are now 20 years' postrepair, and most are doing well. Compared with prosthetic valve replacement, valve-related complications and mortality are improved, ${ }^{1-5}$ and the younger patients with BAV defects can live fully active lives without anticoagulation or other sequalae of "prosthetic valve disease." Yet, imperfections in surgical management remain. Patients with 3 equal-sized sinuses (Figure 2, patient 5) experience greater repair failure/reoperation rates with standard BAV repair, ${ }^{8}$ since a 2-leaflet reconstruction can obstruct the valve, among other problems. Failure to stabilize an enlarged annulus, or annuloplasty by Cabrol's technique, both have been associated with greater failure rates. ${ }^{11,12,15}$ The addition of autologous pericardium as a cusp extension (or as hemi-leaflet replacement ${ }^{9}$ in Sievers type 2 [unicuspid] valves) has predicted repair failure due to pericardial degeneration. ${ }^{10}$ Moreover, other available leaflet tissue substitutes also have performed poorly. ${ }^{28}$ Thus, a repair technique that reduces annular diameter more effectively and better recruits native leaflet tissue to midline coaptation (minimizing the need for pericardium) would be useful. 


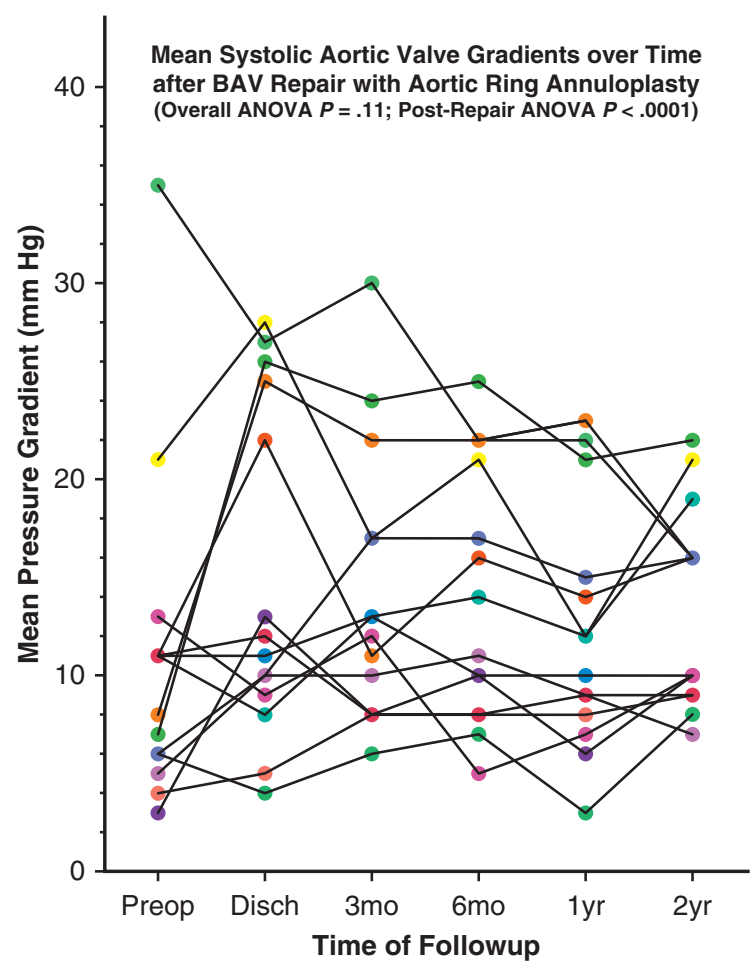

FIGURE 5. Mean valve gradients for individual patients over time after repair. One third of patients had mean gradients in excess of $20 \mathrm{~mm} \mathrm{Hg}$ at discharge, but they all improved to approximately $20 \mathrm{~mm} \mathrm{Hg}$ or less at 2 -years $(P<.001$ by analysis of variance of postrepair data only). $B A V$, Bicuspid aortic valve; ANOVA, analysis of variance; Preop, preoperative; Disch, discharge data.
In the current study, the major geometric remodeling provided by the BAV annuloplasty ring seemed to accomplish these goals. With ring size objectively based on the freeedge length of the nonfused cusp, average annular diameter was reduced to $22 \mathrm{~mm}$, which recruited more leaflet to the center of the valve, allowed better vertical leaflet coaptation, and minimized the need for pericardial augmentation. Most repairs were accomplished using native leaflet alone, with the advantage of maintaining living tissue, and potentially allowing adaptation and remodeling of native leaflets to the physiologic milieu (Figure 5). Even in patient 1 (a reoperative repair with scarred retracted leaflets; https://www. ctsnet.org/article/bicuspid-ring-annuloplasty-and-leaflet-re construction-after-failed-bicuspid-valve-repair-and), enough leaflet was recruited to ensure a long-term competent valve. In addition, regional annular remodeling also was effective, so that a large fused annulus could be reduced to the same size as the nonfused annulus, routinely achieving $180^{\circ}$ commissural geometry in a simpler way than plicating the sinus. $^{29}$ This annuloplasty approach solves the problem of 3 equal sinuses, and routine $180^{\circ}$ root geometry promotes better flow characteristics. ${ }^{30}$ This feature could be especially important in repair of unicuspid valves and intermediate-type bicuspid valves, both of which frequently have 3 equal sinuses.

In this regulated clinical trial, the endpoints were met, with a zero mortality, low residual AI rates, and acceptable mean valve gradients. The data support the algorithm to first

TABLE 2. Baseline and 2-year hemodynamic data for 14 patients undergoing BAV repair

\begin{tabular}{|c|c|c|c|c|c|c|c|c|c|}
\hline \multicolumn{2}{|c|}{ Patient ID } & \multirow{2}{*}{$\begin{array}{c}\text { Leaflets } \\
\text { fused- } \\
\text { Sievers type }\end{array}$} & \multirow{2}{*}{$\begin{array}{c}\text { Preoperative } \\
\text { annular } \\
\text { diameter, } \mathbf{m m}\end{array}$} & \multirow{2}{*}{$\begin{array}{l}\text { Ring } \\
\text { size, } \\
\text { mm }\end{array}$} & \multirow{2}{*}{$\begin{array}{c}\text { Pre/2Y } \\
\text { AI grade } \\
0-4+ \\
\end{array}$} & \multirow{2}{*}{$\begin{array}{c}\text { Pre/2Y } \\
\text { LVEDD, } \\
\text { cm }\end{array}$} & \multirow{2}{*}{$\begin{array}{c}\text { Pre/2Y } \\
\text { LVESD, } \\
\text { cm }\end{array}$} & \multirow{2}{*}{$\begin{array}{c}\text { Pre/2-Y mean valve } \\
\text { gradient, } \\
\text { mm Hg }\end{array}$} & \multirow{2}{*}{$\begin{array}{c}\text { Pre/2-Y } \\
\text { LV mass, } \\
\text { g }\end{array}$} \\
\hline No. & Patient no. & & & & & & & & \\
\hline 1 & 01-001 & LR-1 & 28 & 21 & $3 / 0$ & $5.9 / 4.9$ & $4.0 / 3.4$ & $21 / 21$ & $378 / 197$ \\
\hline 3 & 01-003 & $\mathrm{LR} / \mathrm{RN}-2$ & 30 & 25 & $4 / 1$ & $4.7 / 4.5$ & $2.9 / 2.9$ & $35 / 16$ & $309 / 210$ \\
\hline 4 & 01-004 & LR-1 & 28 & 21 & $3 / 1$ & $5.9 / 5.7$ & $4.1 / 3.2$ & $-/ 12$ & $305 / 273$ \\
\hline 5 & 07-001 & LR-1 & 23 & 19 & $1 / 1$ & $4.5 / 4.5$ & $3.0 / 2.7$ & $8 / 16$ & $186 / 137$ \\
\hline 6 & 01-005 & LR-1 & 26 & 21 & $1 / 1$ & $4.4 / 4.6$ & $2.9 / 2.3$ & $11 / 10$ & $139 / 135$ \\
\hline 7 & $07-002$ & LR-1 & 27 & 23 & $3 / 0$ & $5.6 / 5.0$ & $4.6 / 3.5$ & $6 / 8$ & $311 / 186$ \\
\hline 9 & 01-008 & LR-0 & 28 & 23 & $4 / 1$ & $6.0 / 5.3$ & $3.8 / 3.3$ & $3 / 10$ & $311 / 209$ \\
\hline 10 & 08-001 & LR-1 & 29 & 23 & $4 / 1$ & $7.3 / 4.5$ & $-/ 3.1$ & -19 & $463 / 198$ \\
\hline 11 & 07-003 & LR-0 & 28 & 23 & $3 / 1$ & $5.8 / 4.8$ & $4.7 / 2.6$ & $6 / 16$ & $297 / 187$ \\
\hline 12 & 01-009 & $\mathrm{RN}-0$ & 27 & 21 & $1 / 1$ & $4.2 / 4.5$ & $2.9 / 3.0$ & $13 / 10$ & $157 / 125$ \\
\hline 13 & 07-005 & LR-1 & 25 & 21 & $2 / 1$ & $5.6 / 6.3$ & $4.0 / 4.3$ & $5 / 7$ & $134 / 163$ \\
\hline 14 & 07-006 & LR-1 & 33 & 25 & $1 / 1$ & $5.5 / 5.2$ & $3.4 / 3.5$ & $4 / 9$ & $320 / 278$ \\
\hline 15 & 01-010 & LR-1 & 35 & 23 & $3 / 1$ & $-/ 4.8$ & $-/ 3.1$ & $-/ 13$ & $-/ 171$ \\
\hline \multirow[t]{3}{*}{16} & 07-007 & LR-1 & 29 & 23 & $4 / 2$ & - & - & $7 / 22$ & - \\
\hline & Mean & & 28.3 & 22.3 & $2.6 / 0.9$ & $5.5 / 5.0$ & $3.7 / 3.1$ & $11 / 13$ & $276 / 190$ \\
\hline & SD & & 3.0 & 1.7 & $1.2 / 0.5$ & $0.9 / 0.5$ & $0.7 / 0.5$ & $10 / 5$ & $101 / 47$ \\
\hline
\end{tabular}

Data represent the 14 patients achieving the full 2-year follow-up after BAV repair. The forward slash symbols denote preoperative versus 2-year data, and dashes (-) represent missing data that were imputed as described in the Methods. $2 Y, 2$ Years' postoperative; $A I$, aortic insufficiency; $L V$, left ventricular; $E D D$, end-diastolic diameter; $E S D$, end-systolic diameter; $L$, left coronary leaflet; $R$, right coronary leaflet; $N$, noncoronary leaflet; $S D$, standard deviation. 
achieve adequate effective height $\geq 8 \mathrm{~mm} \mathrm{Hg}$, even if mean gradients are modestly elevated to 20 to $30 \mathrm{~mm} \mathrm{Hg}$. All patients, even those with initially elevated gradients, remained asymptomatic, recovered ventricular function, and, with time, mean valve gradients fell uniformly $(P<.0001)$. The one-third decrease in left ventricular mass after BAV repair was especially impressive. The technique was highly reproducible, applicable to all BAV configurations (Video 1), and could assist in standardizing BAV repair. These satisfactory pilot data justify performance of a pivotal patient study, and an analysis with a larger sample size of 150 patients and a longer follow-up to 10 years currently is being developed.

\section{Conflict of Interest Statement}

Drs Rankin, Mazzitelli, Fischlein, Choi, and Wei are consultants for BSE and report personal fees from proctoring clinical cases in Europe and the United States. Dr Rankin reports minor equity and royalty interests in BSE. Neither the company nor the authors had any contact with or influence on the independent regulatory data, and the analysis was performed by an independent statistician. All other authors have nothing to disclose with regard to commercial support.

\section{References}

1. Aicher D, Fries R, Rodionycheva S, Schmidt K, Langer F, Schafers HJ. Aortic valve repair leads to a low incidence of valve-related complications. Eur J Cardiothorac Surg. 2010;37:127-32.

2. Price J, De Kerchove L, Glineur D, Vanoverschelde JL, Noirhomme P, El Khoury G. Risk of valve-related events after aortic valve repair. Ann Thorac Surg. 2013;95:606-12; discussion 13.

3. de Meester C, Pasquet A, Gerber BL, Vancraeynest D, Noirhomme P, El Khoury G, et al. Valve repair improves the outcome of surgery for chronic severe aortic regurgitation: a propensity score analysis. J Thorac Cardiovasc Surg. 2014;148:1913-20.

4. Yang B, Patel HJ, Sorek C, Hornsby WE, Wu X, Ward S, et al. Sixtenn-year experience of David and Bentall procedures in acute type A aortic dissection. Ann Thorac Surg. 2018;105:779-84.

5. Svensson LG, Batizy LH, Blackstone EH, Gillinov AM, Moon MC, D'Agostino RS, et al. Results of matching valve and root repair to aortic valve and root pathology. J Thorac Cardiovasc Surg. 2011;142:1491-8.e7.

6. Sievers H-H. Excellent results up to 20 years with the Ross operation, albeit with some sobering. J Thorac Cardiovasc Surg. 2019;157:209-10.

7. Schaefers H-J. Reconstruction of the bicuspid aortic valve. Op Tech Thorac Cardiovasc Surg. 2007;12:2-13.

8. Aicher D, Kunihara T, Abou Issa O, Brittner B, Graber S, Schafers HJ. Valve configuration determines long-term results after repair of the bicuspid aortic valve. Circulation. 2011;123:178-85.

9. Aicher D, Bewarder M, Kindermann M, Abdul-Khalique H, Schafers HJ. Aortic valve function after bicuspidization of the unicuspid aortic valve. Ann Thorac Surg. 2013;95:1545-50.

10. Karliova I, Scheider U, Ehrlich T, Schäfers HJ. The fate of pericardial patches in tricuspid and bicuspid aortic cusp repair. Ann Thorac Surg. August 28, 2019 [Epub ahead of print].

11. de Kerchove L, Boodhwani M, Glineur D, Vandyck M, Vanoverschelde JL, Noirhomme P, et al. Valve sparing-root replacement with the reimplantation technique to increase the durability of bicuspid aortic valve repair. J Thorac Cardiovasc Surg. 2011;142:1430-8.

12. Jasinski M, Pisz P, Gocol R, Hudziak D, Plonek T, et al. Bicuspid aortic valve repair-external or subcommissural annuloplasty-13-year experience. J Heart Valve Dis. 2014;23:414-23.

13. Aicher D, Schneider U, Schmied W, Kunihara T, Tochii M, Schafers HJ. Early results with annular support in reconstruction of the bicuspid aortic valve. $J$ Thorac Cardiovasc Surg. 2013;145(3 suppl):S30-4.

14. Habertheuer A, Milewski RK, Bavaria JE, Siki M, Freas M, Desai N, et al. Predictors of recurrent aortic insufficiency in type 1 bicuspid aortic valve repair. Ann Thorac Surg. 2018;106:1316-24.

15. Vallabhajosyula P, Komlo C, Szeto WY, Wallen TJ, Desai N, Bavaria JE Root stabilization of the repaired bicuspid aortic valve: subcommissural annuloplasty versus root reimplantation. Ann Thorac Surg. 2014;97: 1227-34.

16. Mazzitelli D, Pfeiffer S, Rankin JS, Fischlein T, Choi YH, Wahlers T, et al. A regulated trial of bicuspid aortic valve repair supported by geometric ring annuloplasty. Ann Thorac Surg. 2015;99:2010-6.

17. Rankin JS, Bone MC, Fries PM, Aicher D, Schafers HJ, Crooke PS. A refined hemispheric model of normal human aortic valve and root geometry. $J$ Thorac Cardiovasc Surg. 2013;146:103-9.

18. Crooke PS, Beavan LA, Griffin CD, Mazzitelli D, Rankin JS. Design characteristics of a three-dimensional geometric aortic valve annuloplasty ring. Innovations. 2013;8:364-70.

19. Mazzitelli D, Stamm C, Rankin JS, Nobauer C, Pirk J, Meuris B, et al Hemodynamic outcomes of geometric ring annuloplasty for aortic valve repair: a 4-center pilot trial. J Thorac Cardiovasc Surg. 2014;148:168-75.

20. Mazzitelli D, Nobauer C, Rankin JS, Badiu CC, Dorfmeister M, Crooke PS, et al. Early results of a novel technique for ring-reinforced aortic valve and root restoration. Eur J Cardiothorac Surg. 2014;45:426-30.

21. Rankin JS, Mazzitelli D, Fischlein T, Choi Y-H, Pirk J, Pfeiffer S, et al Geometric ring annuloplasty for aortic valve repair during aortic aneurysm surgery: two-year clinical trial results. Innovations. 2018;13:248-53.

22. Vohra HA, Whistance RN, de Kerchove L, Glineur D, Noirhomme P, El Khoury G. Influence of higher valve gradient on long-term outcome after aortic valve repair. Ann Cardiothorac Surg. 2013;2:30-9.

23. Mazzitelli D, Stamm C, Rankin JS, Pfeiffer S, Fischlein T, Pirk J, et al. Leaflet reconstructive techniques for aortic valve repair. Ann Thorac Surg. 2014;98: 2053-60.

24. Zoghbi W. Recommendations for evaluation of the severity of native valvular regurgitation with two-dimensional and Doppler echocardiography. J Am Soc Echocardiogr. 2003;16:777-802.

25. Vohra HA, Whistance RN, De Kerchove L, Punjabi P, El Khoury G. Valve-preserving surgery on the bicuspid aortic valve. Eur J Cardiothorac Surg. 2013;43: 888-98.

26. Salcher M, Nacl H, Kuehne T, Kuehne T, Kelm M. Bicuspid aortic valve disease: systemic review and meta-analysis of surgical aortic valve repair. Open Heart 2016;16:3.

27. Sharma V, Suri RM, Dearani JA, Burkhart HM, Park SJ, Joyce LD, et al Expanding relevance of aortic valve repair-is earlier operation indicated? J Thorac Cardiovasc Surg. 2014;147:100-7.

28. Nordmeyer S, Murin P, Schulz A, Dane F, Nordmeyer J, Kretzschmar J, et al Results of aortic valve repair using decelularized bovine pericardium in congenital surgery. Eur J Cardiothorac Surg. 2018;54:986-92.

29. Schneider U, Schmied W, Aicher D, Giebels C, Winter L, Schafers HJ. Sinus plication to improve valve configuration in bicuspid aortic valve repair-early results. Ann Thorac Surg. 2017;103:580-5.

30. Stephens EH, Hope TA, Kari FA, Kvitting JP, Liang DH, Herfkens RJ, et al. Greater asymmetric wall shear stress in Sievers' type 1/LR compared with 0/LAT bicuspid aortic valves after valve-sparing aortic root replacement. $J$ Thorac Cardiovasc Surg. 2015;150:59-68.

Key Words: bicuspid aortic valve, aortic annuloplasty, aortic valve repair 